\section{Diarréia por parasitas}

\section{Parasites induced diarrheas}

Maria Eugênia Farias Almeida Motta 1 Gisélia Alves Pontes da Silva 2

${ }_{1}$ Universidade Federal de Minas Gerais

2 Departamento Materno Infantil. Centro de Ciências da Saúde da Universidade Federal de Pernambuco. Av. Moraes Rego, s.n. Cidade Universitária. Recife, Pernambuco, Brasil. CEP 50.670-420.

\begin{abstract}
Diarrhea is an important cause of morbidity and mortality in developing countries. The most common etiological agents are viruses and bacteria. This article has the objective of analyzing diarrhea as a clinical symptom of parasitosis. Protozoa and helminthes that may cause diarrhea are discussed, current scientific basis clarifying the pathological and physiological mechanisms causing diarrhea as well as supplementary tests and adequate treatment for each parasite involved are focused.
\end{abstract}

Key words Diarrhea infantile, Parasites
Resumo A diarréia é uma causa importante de morbimortalidade nos países em desenvolvimento. Os agentes etiológicos mais comuns são os vírus e as bactérias. Este artigo tem o objetivo de analisar a ocorrência de diarréia como manifestação clínica de parasitose. Discute-se quais os protozoários e os helmintos que podem causar diarréia, as bases científicas atuais que explicam os mecanismos fisiopatológicos que desencadeiam a diarréia, bem como os exames complementares e o tratamento adequado para cada parasita implicado.

Palavras-chave Diarréia infantil, Parasitos 


\section{Introdução}

A diarréia aguda ainda é uma das mais importantes causas de morbimortalidade na infância em muitos países em desenvolvimento, 1 em especial nos lactentes e pré-escolares. ${ }^{2}$ Nos países industrializados, ela raramente é fatal, embora exerça algum impacto nos setores de saúde e socioeconômico. ${ }^{1} \mathrm{Na}$ maioria dos casos, independentemente da região geográfica, a diarréia tem como agentes etiológicos os vírus e as bactérias. No entanto, algumas vezes, os parasitas intestinais principalmente os protozoários, também podem causar o processo diarréico, nas áreas onde as enteroparasitoses são endêmicas.

Várias espécies de protozoários intestinais foram identificadas, com diferentes graus de patogenicidade. A virulência varia de elevada, como ocorre com o Cryptosporidium $s p$, associado a grande número de infecções sintomáticas, a intermediária, causada pela Giardia lamblia, e inexistente observada pela ausência de patogenicidade de algumas cepas da Entamoeba histolytica.

A diarréia associada com helmintos permanece pouco abordada; a maioria dos helmintos tem sido citada como possíveis causadores de diarréia, especialmente quando a infecção intestinal é intensa. Apenas os vermes que têm um estágio de invasão da mucosa durante o seu desenvolvimento ou que estabelecem um contato íntimo permanente com a mucosa intestinal podem causar diarréia. ${ }^{3}$ Os mais comuns são Trichuris trichiura, Ancylostoma duodenale, Strongyloides stercoralis e Schistosoma mansoni.

Comentários específicos serão feitos em relação aos protozoários e aos helmintos que podem com maior probabilidade, causar diarréia, pois alguns como Taenia solium, Taenia saginata, Ascaris lumbricoides e Enterobius vermicularis, em geral, não causam diarréia, independentemente da quantidade, porque são de localização intraluminal estrita. ${ }^{4,5}$ Quando pacientes com enterobíase queixam-se de diarréia, deve-se fazer pesquisa para Dientamoeba fragilis, protozoário que parasita o cólon, devido à alta razão de coinfecção entre esses dois patógenos. 5 O Enterobius vermicularis causa dano mecânico mínimo à mucosa intestinal, 5 enquanto a fase intestinal do Ascaris lumbricoides é assintomática, mesmo quando a carga parasitária é elevada. Isto se deve a que o verme adulto apenas aloja-se na luz intestinal, sem invadi-la ou aderir-se a ela, consumindo os alimentos ingeridos pelo indivíduo. 5 No entanto, em algumas ocasiões, os antígenos liberados por helmintos intraluminais podem promover a produção de substâncias capazes de causar alterações da função intestinal detectáveis clinicamente. ${ }^{3}$

As parasitoses, em geral, são transmitidas por contato direto fecal-oral ou contaminação de alimentos e água em ambientes com condições sanitárias inadequadas. A população de baixa renda, que reside em ambientes de alta contaminação, com aglomeração intensa de pessoas, sem acesso à saneamento e coleta do lixo, tem um maior risco de se infectar.

Fatores próprios do hospedeiro e dos parasitas contribuem para a instalação e a gravidade da doença. Os indivíduos provenientes de áreas não endêmicas, que não tiveram contato prévio com o parasita, mesmo com a imunidade adequada, podem desenvolver a doença imediatamente após a infecção, caso das "diarréias do viajante" provocadas por parasitas como Giardia lamblia e Schistosoma mansoni. Por outro lado, pessoas imunocomprometidas ou desnutridas costumam apresentar sintomas mais intensos, como ocorre, por exemplo, com a doença por Cryptosporidium parvum. São fatores do parasita, como a carga parasitária e a sua patogenicidade. Quando a infecção é causada por uma grande quantidade de parasitas, é maior a possibilidade de desenvolver sintomas. As cepas de Entamoeba dispar não produzem quaisquer sintomas

Os mecanismos pelos quais os enteropatógenos produzem diarréia são diversos, mas pode-se dividilos entre os que promovem resposta inflamatória sem causar dano morfológico e os que alteram a estrutura da mucosa intestinal, com ou sem invasão tecidual.2 A magnitude e o significado funcional dessas respostas locais são, geralmente, relacionadas ao número de vermes: as infecções causadas por poucos parasitas são comumente assintomáticas, enquanto grande carga parasitária causa manifestações intestinais que podem incluir a diarréia. 3

O tipo de diarréia que se desenvolve parece depender da localização dos vermes. Respostas inflamatórias que ocorrem no intestino delgado proximal causam má absorção e, em consequiência, diarréia osmótica. Quando o cólon é envolvido, distúrbios da absorção de água e exsudação de pus e sangue contribuem para o desenvolvimento de disenteria. ${ }^{3}$

Durante infecções parasitárias podem ocorrer mudanças na motilidade intestinal, que funcionam como uma resposta patológica, conduzindo à diarréia, e também como uma resposta adaptativa do intestino, objetivando alterar o ambiente do parasita e, assim, contribuir para a sua expulsão. ${ }^{6}$ Estudos têm demonstrado um aumento do trânsito intestinal em ratos e cachorros infectados com o nematódeo Trichinella spirallis, coincidindo com o período em que os animais estavam com diarréia.6-8 A diarréia pode, então, ser conseqüência do rápido trânsito de 
secreções gástrica, pancreática, biliar e intestinal para o cólon, que prejudica a absorção dos nutrientes e aumenta a carga osmótica colônica.7,9 Paralelamente, os parasitas presentes no intestino delgado também são propelidos para o cólon. ${ }^{7} \mathrm{~A}$ propulsão intestinal alterada foi associada com deficiência de dissacaridase e inflamação mucosa, mais intensa nos locais onde a maioria dos parasitas se encontravam. 6

É provável, ainda, que os parasitas produzam respostas inflamatórias na mucosa intestinal, que podem ser agudas e auto-limitadas ou crônicas. A liberação local de mediadores da inflamação durante a infecção possivelmente promove a secreção ou inibe a absorção intestinal. ${ }^{2}$ Está bem estabelecido que hipersensibilidade imediata mediada por IgE ocorre em reação a alguns enteropatógenos, o que pode contribuir para a instalação da diarréia e, ao mesmo tempo, para a eliminação de parasitas. ${ }^{10,11}$ Estudo recente sugeriu que os distúrbios de motilidade observados em infecções parasitárias não ocorreriam apenas pela presença do parasita, mas resultariam do processo inflamatório agudo produzido por ele nas células musculares intestinais. 12 Tanto a função motora intestinal como a expulsão de parasitas dependem da presença de linfócitos $\mathrm{T}$; a produção de citocinas por linfócitos Th2 predomina nos locais da infecção parasitária, e a interleucina 4 é crítica na resposta imune à infecções helmínticas, podendo criar um ambiente que é desfavorável ao parasita.13-15 A atividade motora aumentada aliada à inflamação seriam os fatores que contribuiriam para a eliminação do parasita intestinal. 16

Portanto, é possível que a presença de diarréia em algumas helmintíases ocorra apenas em consequiência da tentativa do organismo do hospedeiro em expulsar o agente infeccioso17 - uma ação benéfica a partir do processo inflamatório desencadeado pelo próprio parasita e da atividade motora intestinal acelerada que dele decorre. $\mathrm{O}$ aumento do trânsito intestinal observado em animais infectados fornece evidências de que a resistência natural a um parasita, assim como sua localização no intestino, pode ser influenciada pela motilidade intestinal. 18

\section{Amebíase}

A ingestão de cistos viáveis de Entamoeba histolytica causa a infecção, mas o trofozoíto é a forma que promove a invasão da mucosa intestinal, e assim, a doença por esse parasita. Adultos e crianças são igualmente susceptíveis à infecção, que atinge dez a $12 \%$ da população mundial, mas apenas cerca de $10 \%$ dos infectados apresentam sintomatologia. A ocorrência de infecção assintomática com E. histolytica patogênica em áreas endêmicas explica-se pela elevada prevalência de anticorpos séricos antiameba.

Os trofozoítos amebianos invadem a mucosa colônica e alcançam a submucosa, na qual se multiplicam e provocam lesões necróticas, formando uma úlcera. Esta pode ser puntiforme ou progredir através da lâmina própria para a muscular da mucosa, estendendo-se lateralmente sob a mucosa de aparência normal, caracterizando a úlcera em "botão de camisa".

Os indivíduos, na sua maioria portadores assintomáticos. Outros podem apresentar sintomas discretos, caracterizados por diarréia leve, com fezes líquidas, acompanhada por náuseas e cólicas esporádicas.

Entretanto, a manifestação clínica observada com maior freqüência é a colite amebiana aguda. Em geral, ocorre início gradual com dor abdominal e diarréia com fezes líquidas contendo sangue e muco. Podem estar associados tenesmo, vômitos e flatulência. Os sintomas duram uma a duas semanas. Poucos têm febre, contrastando com a disenteria bacteriana. Ocasionalmente, pode haver diarréia profusa conduzindo à desidratação rápida. A aparência característica de úlceras hemorrágicas puntiformes, com mucosa ao redor relativamente normal à endoscopia do reto ou sigmóide pode auxiliar no diagnóstico. Uma complicação rara é a evolução para colite fulminante, caracterizada por diarréia sanguinolenta intensa e febre, com progressão da ulceração superficial do intestino para necrose transmural.

A amebíase é diagnosticada pela presença de trofozoítos hematófagos (contêm eritrócitos no seu interior) ou cistos, através de exame a fresco das fezes diarréicas ou após fixação e coloração pelo iodo ou tricrômio. $\mathrm{O}$ exame direto deve ser feito imediatamente ou até trinta minutos após a eliminação das fezes, pois os trofozoítos morrem rápidamente no meio externo. A emissão de cistos pode ser intermitente, recomendando-se então, exame de, no mínimo, três amostras de fezes. Os cistos de E. histolytica patogênica e E. dispar - espécie não patogênica não podem ser distinguidos microscopicamente. Por isso, o diagnóstico da colite amebiana deve ser realizado através do achado de trofozoítos hematófagos, que caracterizam a invasão mucosa. A presença exclusiva de cistos nas fezes não é diagnóstica, pois o indivíduo pode ser um portador assintomático de cistos.

A cultura para amebas é um método mais sensível, permitindo a diferenciação entre as formas patogênica e não patogênica, mas não é facilmente disponível. 19 Os testes hematológicos e bioquímicos 
raramente são úteis. É importante lembrar que a invasão por E. histolytica não causa eosinofilia.

A sorologia auxilia no diagnóstico da colite amebiana, sendo positiva em cerca de $90 \%$ dos casos. 20 As técnicas mais utilizadas são o ensaio imunoenzimático (ELISA), difusão em ágar-gel e contraimunoeletroforese. $\mathrm{O}$ resultado positivo sugere amebíase invasiva em atividade, pois os anticorpos antiamebianos negativam após seis a 12 meses do início da infecção.

\section{Tratamento}

O tratamento de indivíduos assintomáticos que eliminam cistos é o ponto mais controverso no manejo da amebíase. Se a sorologia for negativa e a infecção puder ser caracterizada como E. dispar, não se deve tratar.

Os casos sintomáticos devem ser tratados com metronidazol ( 35 a $50 \mathrm{mg} / \mathrm{kg} / \mathrm{dia}$ ), três vezes ao dia, devido à sua alta eficácia e baixa toxicidade. As doses mais baixas são usadas para os quadros leves, por cinco dias consecutivos, e a dose máxima, reservada para a colite amebiana grave, durante dez dias, podendo ser feita por via intravenosa, se necessário. Em seguida, deve-se administrar uma droga de ação luminal para evitar recorrência da infecção. Se não houver boa resposta ao metronidazol, a alternativa é a dehidroemetina (1-1,5mg/kg/dia, máximo de $90 \mathrm{mg}$ ), duas vezes ao dia, por no máximo cinco dias.

\section{Giardíase}

A infecção por Giardia lamblia é endêmica em várias partes do mundo. Mesmo em países industrializados, como os Estados Unidos, é considerada como a enteroparasitose mais frequiente na infância. Nas áreas endêmicas, ocorre principalmente nos primeiros anos de vida. É possível que um menor percentual entre adolescentes e adultos decorra da imunidade adquirida após exposições precoces e sucessivas, resultando em infecções assintomáticas. ${ }^{21-23}$ A baixa dose infectante contribui para a rápida disseminação da infecção nos países pobres, e durante surtos epidêmicos, nos países desenvolvidos. O cisto viável ingerido é a forma infectante sendo capaz de sobreviver em ambiente externo adequado por longos períodos. Os trofozoítos, formas que causam a doença, apenas aderem ao epitélio do enterócito, não apresentando capacidade invasora ou destrutiva direta.

O mecanismo pelo qual a Giardia lamblia causa diarréia e má absorção intestinal permanece controverso e é provável que seja multifatorial. ${ }^{23}$ Ela pode produzir vários graus de dano à mucosa e, ao mesmo tempo, propiciar condições na luz intestinal que poderiam prejudicar a digestão e a absorção de nutrientes. 24

Os fatores mucosos envolvidos na diarréia por giardíase são as alterações na morfologia mucosa, na atividade das dissacaridases e na absorção intestinal. Apesar de ser um parasita predominantemente luminal, os trofozoítos aderem à mucosa e alteram a sua arquitetura no local da adesão, promovendo atrofia vilositária de graus variáveis e aprofundamento das criptas, fato observado em modelos animais. 25,26 Essa anormalidade morfológica tem como conseqüências funcionais a redução da atividade da lactase, da sacarase e da maltase bem como da absorção de água, eletrólitos e glicose.2,26 No entanto, diarréia pode ocorrer na ausência de qualquer alteração microscópica da estrutura intestinal; do mesmo modo a presença de atrofia vilositária parcial moderada ou grave não significa que o indivíduo apresenta diarréia. 27

Os fatores luminais ainda estão pouco elucidados. A giardíase sintomática tem sido associada com grande número de bactérias aeróbicas e anaeróbicas no intestino delgado proximal. ${ }^{28,29} \mathrm{O}$ sobrecrescimento bacteriano pode causar modificação da arquitetura mucosa semelhante a da giardíase. 30

A infecção assintomática é a forma mais comum, principalmente nas áreas onde o parasita é endêmico. 27 Não está claro se portadores crônicos têm episódios diarréicos transitórios não percebidos ou se a infecção foi adquirida recentemente sem produzir sintomas. 30 Isso pode ocorrer devido à fatores do hospedeiro - mecanismos de defesa imunes e não imunes - ou à virulência do parasita. 27

A giardíase aguda em geral é auto-limitada (a cura ocorre em duas a quatro semanas) e caracteriza-se por diarréia em mais de $90 \%$ dos casos (apresentando-se como fezes líquidas, com muco e sem sangue), acompanhada por perda de peso em 60 a $70 \%$ dos indivíduos, náuseas, desconforto e distensão abdominais, flatulência. Mas pode haver evolução para esteatorréia. ${ }^{27} \mathrm{Em} 30$ a 50\% dos casos, a diarréia torna-se persistente e crônica, com conseqüente parada ou retardo do crescimento devido à má absorção intestinal.

Fatores imunológicos do hospedeiro podem ter importância na determinação do curso da infecção. A IgA secretória parece desempenhar papel protetor mais significante, pois os trofozoítos têm localização luminal, apesar de relatar-se a presença de uma protease produzida pelo trofozoíto que atua contra a IgA. Pacientes com hipogamaglobulinemia e imunodeficiências variadas geralmente apresentam maior 
predisposição e manifestações clínicas prolongadas, com baixa resposta terapêutica. Possivelmente, a resposta imune celular atua na produção de IgA secretória anti-giardíase através dos linfócitos T auxiliares (CD4).

O método tradicional de diagnóstico é a pesquisa de cistos e trofozoítos nas fezes. As fezes, após a coleta, devem ser examinadas imediatamente a fresco, coradas pelo iodo. ${ }^{27}$ Quando se utiliza um método de preservação como formalina ou álcool polivinil, as fezes são coradas pelo tricrômio ou pela hematoxilina e os cistos podem ser detectados. $27 \mathrm{O}$ exame seriado das fezes é necessário e aumenta a sensibilidade do método. Uma única amostra de fezes pode detectar cerca de $70 \%$ dos casos, aumentando para $85 \%$ quando três amostras distintas são analisadas. 31 A excreção de cistos é variável a cada dia, sendo por isso importante que fezes coletadas em dias diferentes sejam examinadas. ${ }^{31}$ Para detectar trofozoítas, é preciso examinar fezes aquosas logo após a sua eliminação. 27 Trofozoítas também foram encontrados no fluído duodenal em $44 \%$ dos casos estudados por Goka et al.;31 esse exame pode ser feito através do Enterotest, por tubagem duodenal ou nos pacientes que irão submeter-se à endoscopia digestiva alta. ${ }^{27}$ Biópsias de tecido do intestino delgado proximal também podem ser obtidas por via endoscópica. 32 Os métodos invasivos serão usados quando houver forte suspeita diagnóstica, e os exames parasitológicos de fezes forem constantemente negativos. 27

É possível a detecção dos antígenos da Giardia lamblia em espécimes fecais, utilizando-se o ensaio imunoenzimático (ELISA).33,34 Esse método apresenta maior sensibilidade e especificidade que o exame das fezes à procura de cistos ou trofozoítos. 27

Detecção de anticorpos anti-Giardia no soro tem pouca contribuição para o diagnóstico. 35 IgM identifica infecção aguda mesmo nas áreas endêmicas. 36 Os títulos são aumentados apenas em indivíduos com infecção contínua, com redução rápida após eliminação da infecção,37 mas a sensibilidade e a especificidade diminuem na criança com diarréia persistente. ${ }^{27} \mathrm{IgG}$ é encontrada em indivíduos infectados; no entanto, em áreas endêmicas, ela não distingue entre infecção atual e passada, provavelmente devido à exposição contínua. 27

O tratamento de eleição é feito com os derivados nitroimidazólicos - metronidazol ou tinidazol - que têm eficácia elevada. O metronidazol é feito na dose de $15-20 \mathrm{mg} / \mathrm{kg} / \mathrm{dia}$, duas vezes ao dia, por sete ou dez dias consecutivos. O tinidazol tem a vantagem de ser usado em dose única $(50 \mathrm{mg} / \mathrm{kg})$, mas seus efeitos colaterais são mais intensos. $\mathrm{O}$ albendazol também tem sido usado atualmente; a dose de $400 \mathrm{mg} / \mathrm{dia}$, três ou cinco dias consecutivos, tem eficácia melhor ( 81 a $95 \%$ ) do que as doses únicas de 400, 600 ou $800 \mathrm{mg}$; ele é comparável ao metronidazol (97 a 100\%).

\section{Criptosporidíase}

O Cryptosporidium parvum é uma importante causa de doença diarréica aguda em indivíduos imunocompetentes, embora seja comum em pacientes com Síndrome da Imunodeficiência Adquirida (SIDA) e outras doenças imunodepressoras, conduzindo-os a diarréia crônica.

O uso rotineiro de cloro na água de beber é relativamente ineficaz para matar os oocistos, forma infectante desse protozoário. ${ }^{38}$ Foi detectada uma soroprevalência de $95 \%$ aos dois anos de vida no Nordeste do Brasil. ${ }^{39}$ Bezerros são fonte de infecção humana e, por isso, o consumo de leite de vaca não pasteurizado pode causar infecção. 40

No hospedeiro imunocompetente, a replicação do parasita ocorre principalmente na borda apical do enterócito, no jejuno baixo e íleo, local de aderência do Cryptosporidium parvum, podendo-se observar atrofia vilositária variável (leve a grave) no ponto de contato.2,41 Quando grande quantidade desse protozoário está presente nos intestinos delgado e grosso, é possível causar redução na superfície intestinal disponível para a absorção;42 mas não existe evidência direta que comprove essa hipótese. Também pode ocorrer invasão da mucosa intestinal.

A diarréia poderia ser devido à má absorção por atrofia das vilosidades, com conseqüente redução da área de absorção e da atividade das dissacaridases. 41

A gravidade e a duração do quadro clínico são influenciadas pelo estado imune do hospedeiro. 38 Após período de incubação de aproximadamente uma semana, o indivíduo começa a apresentar diarréia aquosa, de odor fétido, sem muco ou sangue. 43,44

No hospedeiro imunocompetente, causa uma diarréia profusa e aquosa, às vezes com muco, que é auto-limitada, durando de dez a 14 dias, mas pode permanecer por mais de um mês. 41,45 Há queixas freqüentes de dor abdominal tipo cólica, flatulência, náuseas e vômitos, acompanhados por sintomas gerais como anorexia, mialgia, cefaléia, astenia e indisposição; a febre, se presente, é baixa. A alimentação pode exacerbar a diarréia e a dor abdominal. Raramente é grave e prolongada, associando-se, nesses casos, com perda de peso importante. Em geral, ocorre recuperação espontânea 45 e parece desen- 
volver-se imunidade permanente, pois não têm sido registrados casos de infecções recorrentes.

No paciente imunocomprometido, é comum manifestar-se como uma doença grave, prolongada, com perda de dois a três litros de fezes aquosas, 45 má absorção, desidratação e desnutrição significantes, que pode culminar com o óbito quando não se consegue o controle das perdas fecais. Os sintomas dependem da variação no estado imunológico, do estado nutricional e da terapia realizada. Também é possível ocorrer a cura espontânea. 46,47

O diagnóstico é confirmado pela identificação de oocistos nas fezes, sendo necessário três ou mais amostras fecais porque a excreção de oocistos é variável ao longo de um dia e entre os dias. $48 \mathrm{~A}$ aspiração do fluído duodenal ou escovação do intestino delgado podem ser realizados se o paciente submeter-se a uma endoscopia digestiva alta, especialmente quando a biópsia intestinal é contra-indicada. O método mais efetivo e usado para identificar os oocistos nas amostras de fezes é a coloração álcool ácido resistente, que dá cor vermelha aos oocistos ${ }^{49-}$ 51 Outras técnicas de coloração incluem Giemsa, PAS e tricrômio, que colorem os oocistos ou agem como coloração negativa ${ }^{52,53}$ Vários métodos recentes têm sido propostos, porém a coloração de fixação ácida permanece a técnica de escolha. ${ }^{54}$ Sangue e leucócitos são encontrados raramente na diarréia por Cryptosporidium parvum.

Os testes sorológicos são mais usados em estudos epidemiológicos e têm pouca aplicação diagnóstica. Os anticorpos podem ser detectados por imunofluorescência indireta e ELISA. Níveis elevados de IgM e/ou IgG são detectados duas semanas após o início dos sintomas, persistindo por períodos prolongados, mas IgM sugere possível reexposição nas áreas endêmicas. A imunofluorescência com anticorpo monoclonal é disponível comercialmente e tem altas sensibilidade e especificidade, permitindo a detecção de portadores assintomáticos e de fontes ambientais de contaminação55 Existem métodos mais recentes usando técnicas moleculares. A reação em cadeia polimerase é capaz de detectar até um único parasita, e é muito específica. 56

A espiramicina na dose de $40-50 \mathrm{mg} / \mathrm{kg} / \mathrm{dia}$, de seis em seis horas, por dez dias consecutivos é uma droga efetiva para pacientes imunocompetentes, 57 mas parece ter pouco ou nenhum efeito nos imunodeprimidos. No entanto foi demonstrado, em crianças portadoras assintomáticas de Cryptosporidium, com o sistema imune competente ou suprimido, que o uso de espiramicina na dose de $100 \mathrm{mg} / \mathrm{kg} /$ dia, durante 14 dias, impediu o aparecimento de sintomas; as não tratadas desenvolveram sintomas gastrintestinais posteriormente, independentemente do seu estado imunológico. 58 Em duas crianças com câncer e diarréia associada ao Cryptosporidium, o uso de azitromicina promoveu a melhora imediata do sintoma. 59 Nos pacientes com SIDA, a paramomicina parece promover melhores resultados. 60

\section{Himenolepíase}

É uma helmintíase intestinal causada por cestóides das espécies Hymenolepis nana e Hymenolepis diminuta. A sua transmissão dá-se pela ingestão de ovos embrionados. Os ovos liberam larvas que aderem à parede do intestino delgado, onde maturam até verme adulto.

Quase todos os indivíduos infectados são assintomáticos, no entanto, infestações graves podem causar inflamação intestinal e pequenas ulcerações devido à invasão das vilosidades da mucosa. ${ }^{3}$ Clinicamente, o paciente apresenta diarréia, às vezes com muco, dor abdominal em cólica, meteorismo, anorexia, perda de peso e cefaléia.

O diagnóstico é feito com a identificação de ovos nas fezes de indivíduos infectados. Vários exames de fezes podem ser necessários para detectar a infecção, pois a eliminação de ovos às vezes é irregular. O ELISA tem sido usado na detecção de anticorpos no soro de indivíduos infectados, mas tem baixa especificidade devido aos resultados falso positivos em indivíduos com cisticercose, não sendo recomendado para uso rotineiro na clínica.

O praziquantel 20 a $25 \mathrm{mg} / \mathrm{kg}$ dose única é a droga de escolha para o tratamento, com eficácia em torno de $90 \%$ após duas semanas e em torno de $97 \%$ após quatro semanas. A niclosamida $(200 \mathrm{mg} / \mathrm{dia})$, por seis dias seguidos é uma opção terapêutica, com índices de cura de cerca de 60 a $80 \%$.

\section{Tricuríase}

É causada pelo Trichuris trichiura, parasita comum em regiões quentes e úmidas, onde as chuvas ocorrem durante todo o ano. A transmissão ocorre a partir da ingestão de ovos embrionados.

As larvas amadurecem no intestino delgado e migram para o cólon proximal. Nas infecções graves, os vermes podem ser encontrados do íleo terminal ao reto, tornando a mucosa edematosa, friável e com facilidade de sangramentos. As alterações da mucosa são encontradas apenas no local de aderência do parasita e consistem de petéquias ou hemorragia subepitelial, destruição celular e infiltração su- 
perficial com eosinófilos, linfócitos e células plasmáticas. Trichuras trichiura provoca reação de hiper-sensibilidade imediata na mucosa colônica, que pode estar envolvida na patogênese da síndrome disentérica por esse parasita. 61

Dependendo da carga de parasitas, a infecção pode ser assintomática ou associada com diarréia, em geral crônica, disenteria ou retardo de crescimento.62 Se a infecção é exclusivamente luminar, não há sintomas. Se a carga de parasitas é pequena, o indivíduo pode apresentar desconforto e distensão abdominal, náusea, flatulência e diarréia.62 Quando a carga de parasitas é moderada, desenvolve-se um quadro de colite crônica com dor abdominal baixa, diarréia, distensão abdominal, anorexia e perda de peso. A disenteria é comum e clássica nas crianças com intensa carga parasitária. ${ }^{3}$ A diarréia é profusa, sanguinolenta, com muco e pus, acompanhada por anorexia, perda de peso, dor epigástrica, cólicas, vômitos, flatulência, tenesmo, urgência e prolapso retal, característico dessa síndrome; as crianças são freqüentemente stunted e de baixo peso, anêmicas e malnutridas. ${ }^{62}$ A lesão na mucosa colônica provoca uma reação inflamatória semelhante àquela vista na colite ulcerativa idiopática; por isso deve-se incluir a tricuríase no diagnóstico diferencial de colite, mesmo nas áreas onde essa parasitose não é endêmica. ${ }^{3}$

O diagnóstico é feito por intermédio do exame das fezes, direto ou de amostras conservadas em solução salina, a partir do achado de parasitas adultos ou ovos. ${ }^{62}$ A retossigmoidoscopia ou colonoscopia podem demonstrar uma mucosa friável, hiperemiada, percebendo-se usualmente os locais de aderência ou o próprio parasita adulto pendendo na luz intestinal.62 No enema opaco os vermes podem ser vistos como translucências lineares ou espirais.

É uma das helmintíases que tem pior resposta à terapêutica. O pamoato de oxipirantel $(20 \mathrm{mg} / \mathrm{kg} /$ dia), duas vezes por dia, dois dias seguidos, é recomendado como droga de escolha, com taxas de cura de 70 a $90 \%$. O mebendazol (100mg) duas vezes por dia, três dias seguidos, tem efeito ovicida incompleto, mas é eficaz contra os parasitas adultos. $\mathrm{O}$ albendazol é menos efetivo que o mebendazol para eliminar essa parasitose; dose única $(400 \mathrm{mg})$ tem efeito ovicida incompleto e baixas razões de cura.

\section{Ancilostomíase}

É causada por duas espécies de nematódeos: o Ancylostoma duodenale e o Necator americanus. A infecção ocorre por via percutânea, durante contato com solo contendo material fecal contaminado com larvas filarióides, ou por via oral, após ingestão dessas larvas. Durante a fase intestinal da infecção, os parasitas adultos aderem à mucosa duodenal, onde causam danos mecânicos e químicos. Os danos mecânicos resultam do envolvimento da mucosa pela cápsula bucal do parasita, que, para a sua nutrição, suga sangue da mucosa originando daí pequenas úlceras, edema e infiltrado leucocitário, e aumento do peristaltismo. Os danos químicos ocorrem devido à ação de várias enzimas hidrolíticas derivadas do parasita.

Por causa das lesões mecânicas, surge diarréia, em geral leve, ${ }^{3}$ raramente com sangue, dores abdominais, às vezes no epigástrio, anorexia, naúseas e vômitos, anemia, com melena presente nos casos graves. 62

O diagnóstico de certeza é feito através do exame das fezes, por exame direto ou amostras fecais preservadas em solução salina, a partir da demonstração de ovos de ancilostomídeos. ${ }^{62}$ Métodos de concentração como flutuação em sulfato de zinco ou a técnica de éter-formalina são úteis, especialmente nas infecções da luz intestinal.62 A contagem de ovos pode ser feita pelo método de Kato-Katz.

O tratamento medicamentoso de escolha permanece sendo o mebendazol, na dose de $100 \mathrm{mg}$, duas vezes por dia, três dias consecutivos, que promove efeito ovicida completo. O albendazol é a droga alternativa de primeira escolha, na dose única de $400 \mathrm{mg}$, ou por três dias consecutivos, com eficácia variável de $63-100 \%$. O levamisol $(2,5 \mathrm{mg} / \mathrm{kg})$ em dose única, é eficaz para reduzir o número de ovos, assim como o pamoato de pirantel (10 ou $11 \mathrm{mg} / \mathrm{kg}$, máximo de $1 \mathrm{~g}$ ) em dose única ou por três dias seguidos, ambos com efeitos colaterais leves.

\section{Estrongiloidíase}

O Strongyloides stercoralis é o helminto que pode utilizar o maior número de recursos para que sua transmissão se efetive. A infecção ocorre a partir da penetração de larvas filarióides através da pele; portanto, a contaminação peridomiciliar, propiciada pelas condições de moradia e sanitárias inadequadas, favorece a disseminação do parasita. A transmissão por via oral, a partir da ingestão de larvas, é mais rara. Após o ciclo pulmonar, o verme chega ao duodeno e jejuno sob a forma adulta.

Nos indivíduos imunocompetentes, a estrongiloidíase pura, não complicada é, em geral, uma infecção assintomática e não causa diarréia. ${ }^{3}$ No entanto, existe a possibilidade de hiperinfecção, que ocorre quando o indivíduo é infectado por um 
número excessivo de larvas filarióides, cuja instalação é facilitada por situações de imunodepressão. Quando a infecção é disseminada e ocorre dano em todo o trato gastrintestinal, a diarréia resultante terá componentes osmótico, exsudativo, motor e bacteriano, sendo, portanto, multifatorial. ${ }^{3}$ No intestino delgado, os parasitas adultos podem causar três tipos de lesões: enterite catarral (secreção mucóide abundante recobrindo a mucosa), enterite edematosa (espessamento da parede intestinal e achatamento das dobras mucosas devido à edema da submucosa) e enterite ulcerativa (rigidez da parede intestinal por edema e fibrose secundários à inflamação prolongada com a mucosa podendo apresentar atrofia, erosões e ulcerações). 63

A maioria das infecções em áreas endêmicas são assintomáticas. ${ }^{62,64}$ Sintomas agudos provavelmente refletem a intensidade da infecção. 60 Podem ocorrer episódios curtos de diarréia intercalados com constipação intestinal. 60 A diarréia usualmente consiste de fezes semiformadas, sem sangue. 65 Presença de sangue oculto nas fezes é ocasional, ocorrendo em indivíduos com infecção crônica. Diarréia grave, acompanhada por dor abdominal tipo cólica, é incomum. ${ }^{66}$ Síndrome de má absorção é associada com parasitismo intestinal maciço.67,68 $\mathrm{Na}$ hiperinfecção, a diarréia é profusa e pode ser aquosa, com muco ou com sangue. Nesses casos, a diarréia deve-se às erosões, ulcerações e edema causados pela grande quantidade de parasitas na mucosa dos intestinos delgado e grosso. ${ }^{69}$ Essas alterações mucosas predispõem o paciente à infecções por bactérias, ${ }^{3}$ e após períodos variados de diarréia, à instalação de íleo paralítico.

O diagnóstico etiológico da infecção é feito com o exame parasitológico de fezes, usando-se o método de Baermann, que é mais sensível que a microscopia direta. 70 A larva rabditóide é a forma identificada mais comumente, mas larvas filarióides, parasitas adultos fêmeas e ovos podem ser encontrados. A imunofluorescência indireta detecta anticorpos séricos IgG para antígenos de superfície de larvas filarióides, mas o ELISA tem sensibilidade maior, (cerca de 90\%). 71

O tiabendazol é a droga de escolha para o tratamento, 71 podendo ser usado na dose única de $(50 \mathrm{mg} / \mathrm{kg}$ ) (máximo de $3 \mathrm{~g}$ ) ou $25 \mathrm{mg} / \mathrm{kg}$, duas vezes por dia, dois dias consecutivos, devendo ser repetido após sete dias. Apesar de eficaz, essa droga tem elevado percentual de efeitos colaterais, o que pode impossibilitar o cumprimento da prescrição. $\mathrm{O}$ fracionamento em dois dias pode reduzir o aparecimento de reações adversas. Como alternativa, pode-se usar o albendazol, na dose de $400 \mathrm{mg} /$ dia, por três dias seguidos.

\section{Esquistossomose mansônica}

O Schistosoma mansoni é um trematódeo que causa infecção a partir do contato com água fresca contaminada por cercárias, acometendo viajantes ou indivíduos sem exposição prévia ao parasita. Nas áreas endêmicas, a exposição ocorre em indivíduos jovens. A doença é relacionada à intensidade da infecção: indivíduos expostos a altas cargas de vermes estão mais propensos a desenvolver a doença e são responsáveis pela maior contaminação do ambiente com ovos e, assim, com a manutenção da endemicidade.

Os ovos produzidos por vermes adultos presentes no plexo mesentérico e a migração das larvas são as principais causas da doença em humanos. ${ }^{3} \mathrm{O}$ embrião vivo dentro do ovo secreta material antigênico continuamente por duas a quatro semanas, induzindo à sensibilização do hospedeiro, e recruta células inflamatórias, formando o granuloma esquistossomótico. A secreção antigênica cessa apenas quando o embrião dentro do ovo morre.

A maioria das infecções são assintomáticas. Nos indivíduos provenientes de áreas não endêmicas, a esquistossomose aguda cursa com sinais e sintomas 3,72 e dura em média de um a dois meses. Os sintomas, em geral, instalam-se abruptamente, com febre, astenia, anorexia, sudorese, dor abdominal em cólicas e diarréia com sangue. ${ }^{3}$ Pode haver hepatoesplenomegalia discreta, com dor à palpação do fígado, e aumento de gânglios periféricos. ${ }^{3}$ No reto e no sigmóide observam-se edema intenso, eritema, áreas hemorrágicas e pequenas úlceras. ${ }^{3}$ No íleo e até no duodeno e no jejuno, que nunca são afetados em outros estágios da doença, lesões semelhantes também podem ser encontradas. 3

$\mathrm{Na}$ esquistossomose crônica, a sintomatologia é variável. Muitos pacientes permanecem assintomáticos, embora os sintomas possam aparecer a qualquer época. Um dos mais comuns é a diarréia, periódica, às vezes com muco e sangue e tenesmo, alternando com constipação intestinal.

O diagnóstico definitivo depende da demonstração de ovos de parasitas nas fezes. Às vezes, são necessários vários exames para conseguir detectálos. 73 A contagem de ovos é útil para avaliar a intensidade da infecção e deve ser verificado também a viabilidade dos ovos - vivos imaturos (postura com menos de seis dias), vivos maduros (postura em seis a 18 dias) e mortos. ${ }^{73}$ Caso não se evidenciem ovos nas fezes, a biópsia retal pode ser solicitada, permitindo o achado dos ovos e do granuloma. Os testes 
sorológicos também auxiliam no diagnóstico dos indivíduos com suspeita da doença, provenientes de áreas não endêmicas.

O praziquantel, na dose de $40 \mathrm{mg} / \mathrm{kg}$ em dose única, é citado por alguns autores como a droga principal no tratamento da esquistossomose, $74 \mathrm{com}$ maior eficácia e rapidez de ação do que a oxamniquina (dose única de $20 \mathrm{mg} / \mathrm{kg}$ ), observando-se cura parasitológica em torno de $80 \%$.

Sendo a transmissão das parasitoses vinculada diretamente à precária condição ambiental do indivíduo, a prevenção primária das infecções está associada à implementação de programas de saneamento básico e à orientação adequada das medidas higiênicas pelos profissionais de saúde. Se a primeira medida foge a qualquer apelo ou vontade do médico, ainda que inúmeras pesquisas clínicas apontem a sua necessidade imperiosa para a melhoria da saúde da população, a outra é um dever do qual ele não se pode omitir na sua prática diária, devendo estar disponível e apto para contribuir com o nível de educação sani- tária de seus pacientes.

Uma vez que a doença parasitária tenha se instalada, o tratamento deve ser realizado, como forma de prevenir eventuais alterações nutricionais secundárias à espoliação de nutrientes. Quanto à prevenção secundária, o uso periódico e coletivo de anti-pararasitários ainda permanece controverso. Uma análise criteriosa da situação é fundamental. Se os indivíduos são apenas portadores do parasita, sem apresentar sintomas, a melhor opção é não instituir terapêutica indiscriminada, principalmente porque a carga parasitária da maioria dos infectados assintomáticos é pequena para causar morbidade, e o tratamento traria pouco benefício. 75 Individualmente, se os sintomas são leves, mas repetitivos, podendo alterar futuramente, o estado nutricional ou comprova-se infecção crônica associada com comprometimento pôndero-estatural atual, na ausência de outro fator causal, o tratamento da parasitose deve ser realizado. 75

\section{Referências}

1. Syder JD, Merson MH. The magnitude of global problem of acute diarrheal disease: a review of active surveillance data. Bull World Health Organ 1982; 60: 605-13.

2. Farthing MJ. Acute diarrhea: pathophysiology. In: Gracey M, Walker-Smith JA, editors. Diarrheal diseases. New York: Lippincott; 1997. p. 55-74.

3. Genta RM. Diarrhea in helminthic infections. Clin Infect Dis 1993; 16 Suppl 2: S122-9.

4. Barry M, Cappello M. Cestodes. In: Blaser MJ, Smith PD, Ravdin JI, Greenberg HB, Guerrant RL, editors. Infections of the gastrointestinal tract. New York: Raven ; 1995. Chap 75, p. $1155-66$

5. Gopinath R, Keystone JS. Ascariasis, trichuriasis, and enterobiasis. In: Blaser MJ, Smith PD, Ravdin JI, Greenberg HB, Guerrant RL, editors. Infections of the gastrointestinal tract. New York: Raven; 1995. Chap 76, p. 1167-78.

6. Castro GA, Badial-Aceves F, Smith JW, Dudrick SJ, Weisbrodt. Altered small bowel propulsion associated with parasitism. Gastroenterology 1976; 71: 620-5.

7. Cowles VE, Sarna SK. Effect of T. spiralis infection on intestinal motor activity in the fasted state. Am J Physiol 1990; 259: G693-701.

8. Palmer JM, Weisbrodt NW, Castro GA. Trichinella spiralis: intestinal myoeletric activity during enteric infection in the rat. Exp Parasitol 1984; 57: 132-41.

9. CowlesVE, Sarna SK. Trichinella spiralis infection alters small bowel motor activity in the fed state. Gastroenterology 1991; 101: 664-9.

10. Baird AW, O'Malley KE. Epithelial ion transport-possible contribution to parasite expulsion. Parasitol Today 1993; 9: 141-3.

11. Barrett KE, Neva FA, Gam AA, Cicmanec J, London WT,
Phillips JM, Metcalfe DD. The immune response to nematode parasites: modulation of mast cell numbers and function during Strongyloides stercoralis infections in non-human primates. Am J Trop Med Hyg 1988; 38 : 574-81.

12. Castex N, Fioramonti J, Lahitte JD, Luffau G, More J, Bueno L. Brain fos expression and intestinal motor alterations during nematode-induced inflammation in the rat. Am J Physiol 1998; 274: G210-6.

13. Svetic A, Madden KB, Zhou XD, Lu P, Katona IM, Finkelman FD, Urban JF, Gause WC. A primary intestinal helminthic infection rapidly induces a gut-associated elevation of Th2-associated cytokines and IL-3. J Immunol 1993; 150: 3434-41

14. Urban JF, Maliszewski CR, Madden KB, Katona IM, Finkelman FD. IL-4 treatment can cure estabilished gastrointestinal nematode infections in immunocompetent and immunodeficient mice. J Immunol 1995; 154: 467584.

15. Vallance B, Blennerhassett P, Collins S. Increased intestinal muscle contractility and worm expulsion in nematodeinfected mice. Am J Physiol 1997; 272: G321-7.

16. Nawa Y, Ishikawa K, Tsuchiya K, Horii Y, Abe T, Khan A, Bing-Shi, Itoh H, Ide H, Uchiyama F. Selective effector mechanisms for the expulsion of intestinal helminths. Parasite Immunol 1994; 16: 333-8.

17. Schanbacher LM, Nations JK, Weisbrodt NW, Castro GA Intestinal myoeletric activity in parasitized dogs. Am J Physiol 1978; 234: R188-95.

18. Alizadeh H, Castro GA, Weems WA. Intrinsec intestinal propulsion in the Guinea pig during parasitis with Trichinella spiralis. Gastroenterology 1987; 93: 784-90. 
19. Irusen EM, Jackson TF, Simjee AE. Asymptomatic intestinal colonization by pathogenic E. hystolitica in amebic liver abscess: prevalence, response to therapy, and pathogenic potential. Clin Infec Dis 1992; 14: 889-93.

20. Healy GR. Immunologic tools in the diagnosis of amebiais: epidemiology in the United States. Rev Infect Dis 1986; 8: 239-45.

21. Farthing MJ, Mata L, Urrutia JJ, Kronmal RA. Natural history of Giardia infection of infants and children in rural Guatemala and its impact on physical growth. Am J Clin Nutr 1986; 43: 395-405.

22. Istre GR, Dunlop TS, Gaspar GB, Hopkins RS. Waterbone giardiasis at a mountain resort: evidence for acquired immunity. Am J Public Health 1984; 74: 602-4.

23. Webster AD. Giardiasis and immunodeficiency diseases. Trans R Soc Trop Med Hyg 1980; 74: 440-3.

24. Katelaris PH, Farthing MJ. Diarrhoea and malabsorption in giardiasis: a multifactorial process. Gut 1992; 33: 295-7.

25. Buret A, Gall DG, Olson ME. Growth, activities of enzymes in the small intestine and ultrastructure of the microvillus border in gerbils infected with Giardia duodenalis. Parasitol Res 1991; 77: 109-14.

26. Buret A, Hardin JA, Olson ME, Gall DG. Pathophysiology of small intestinal malabsorption in gerbil infected with Giardia lamblia. Gastroenterology 1992; 103: 506-13.

27. Farthing MJ. Giardiasis. Gastroenterol Clin North Am 1996; 25: 493-515.

28. Tandon BN, Tandon RK, Satpathy BK, Shriniwas. Mechanism of malabsorption in giardiasis: a study of bacterial flora and bile salt deconjugation in upper jejunum. Gut 1977; 18: 176-81

29. Tomkins AM, Wright SG, Drasar BS, James WP. Bacterial colonization of jejunal mucosa in giardiasis. Trans R Soc Trop Med Hyg 1978; 72: 33-6.

30. Farthing MJ. Giardia lamblia. In: Blaser MJ, Smith PD, Ravdin JI, Greenberg HB, Guerrant RL, editors. Infections of the gastrointestinal tract. New York: Raven; 1995. Chap 71, p.1081-1105.

31. Goka AK, Rolston DD, Mathan VI, Farthing MJ. The relative merits of faecal and duodenal juice microscopy in the diagnosis of giardiasis. Trans R Soc Trop Med Hyg 1990; 84: 66-7.

32. Bending DW. Diagnosis of giardiasis in infants and children by endoscopic brush cytology. J Pediatr Gastroenterol Nutr 1989; 8: 204-6.

33. Ungar BL, Yolken RH, Nash TE, Quinn TC. Enzymelinked immunosorbent assay for detection of Giardia lamblia in fecal specimens. J Infect Dis 1984; 149: 90-7.

34. Wienecka J, Olding-Stenkvist E, Schriider H, Huldt G. Detection of Giardia antigen in stool samples by a semiquantitative enzyme imunoassay (EIA) test. Scand J Infect Dis 1989; 21: 443-8.

35. Farthing MJ. Immunopathology of giardiasis. Springer Semin Immunopathol 1990; 12: 269-82.

36. Sullivan PB, Neall G, Cevallos AM, Farthing MJ. Evaluation of specific serum anti-Giardia IgM antibody response in diagnosis of giardiasis. Trans R Soc Trop Med Hyg 1991; 85: 748-9.

37. Nash TE, Herrington DA, Losonsky GA, Levine MM. Experimental human infections with Giardia lamblia. J Infect Dis 1987; 156: 974-84.

38. Mackenzie WR. A massive outbreak in Milwaukee of Cryptosporidium infection transmitted through the public water supply. N Engl J Med 1994; 331: 161-7.
39. Zu S-X, Li JF, Barrett LJ, Fayer R, Shu SY, McAuliffe JF, Roche JK, Guerrant RL. Seroepidemiologic study of Cryptosporidium infection in children from rural communities of Anhui, China and Fortaleza, Brazil. Am J Trop Med Hyg 1994; 51: 1-10.

40. Adal KA, Sterling CR, Guerrant RL. Cryptosporidium and related species. In: Blaser MJ, Smith PD, Ravdin JI, Greenberg HB, Guerrant RL, editors. Infections of the gastrointestinal tract. New York: Raven; 1995. Chap 72, p.1107-28.

41. Chacín-Bonilla L. Cryptosporidiasis in humans. Review. Invest Clin 1995; 36: 207-50.

42. Marcial MA, Madara JL. Cryptosporidium: cellular localization, structural analysis of absorptive cell-parasite membrane interactions in Guines pigs and suggestion of protozoan transport by M cells. Gastroenterology 1986; 90: 583-94.

43. Jokipii L, Jokipii AM. Timing of symptoms and oocist excretion in human cryptosporidiasis. N Engl J Med 1986; 315: 1643-7.

44. Jokipii AM, Hemilá M, Jokipii L. Prospective study of acquisition of Cryptosporidium, Giardia lamblia, and gastrointestinal illness. Lancet 1985; 2: 487-9.

45. Juckett G. Intestinal protozoa. Am Fam Phys 1996; 53 : 2507-18

46. Stine KC, Harris FA, Lindsey NJ, Cho CT. Spontaneous remission of cryptosporidiosis in a child with acute lymphocitic leukemia. Clin Pediatr 1985; 24: 722-4.

47. Saltzberg DM, Kotloff KL, Newman JL, Fastiggi R. Cryptosporidium infection in acquired immunodeficiency syndrome: not always a poor prognosis. J Clin Gastroenterol 1991; 13: 94-7.

48. Goodgame RD, Genta RM, Clinton White A, Chappell CL. Intensity of infection in AIDS-associated cryptosporidiosis. J Infect Dis 1993; 167: 704-9.

49. Smith HV, Mc Diarmid A, Smith AL, Hinson AR, Gilmour RA. An analysis of staining methods for the detection of Cryptosporidium spp. Oocysts in water-related samples. Parasitology 1989; 99: 323-7.

50. Garcia LS, Bruckner DA, Brewer TC, Shimizu RY. Techniques for the recovery and identification of Cryptosporidium oocysts from stools specimens. J Clin Microbiol 1983; 18: 185-90.

51. Garza D, Hopfer RL, Eichelberger C, Eisenbach S, Fainstein V. Fecal staining methods for screening Cryptosporidium oocysts. J Med Technol 1984: 147: 824-8.

52. Casemore DP. Laboratory methods for diagnosing cryptosporidiosis. J Clin Pathol 1991; 44: 445-51.

53. Garcia LS, Current WL. Cryptosporidiosis: clinical features and diagnosis. Crit Rev Clin Lab Sci 1989; 27: 439-60.

54. MacPherson DW, McQueen R. Cryptosporidiosis: multiattribute evaluation of six diagnostic methods. J Clin Microbiol 1993; 31: 198-202.

55. Garcia LS, Sheim AC, Bruckner DA. Evaluation of a new monoclonal antibody combination reagent for direct fluorescence detection of Giardia cysts and Cryptosporidium cysts in human fecal specimens. J Clin Microbiol 1992; 30: 3255-7.

56. Laxer MA, D'Nicuola ME, Patel RJ. Detection of Cryptosporidium parvum DNA in fixed, paraffin-embedded tissue by the polymerase chain reaction. Am J Trop Med Hyg 1992; 47: 450-5.

57. Fafard J, Lalonde R. Long-standing symptomatic cryptosporidiosis in a normal man: clinical response to spi- 
ramycin. J Clin Gastroenterol 1990; 12: 190-1.

58. Pettoello-Mantovani M, Di Martino L, Dettori G, Vajro P, Scotti S, Ditullio MT, Guandalini S. Asymptomatic carriage of intestinal Cryptosporidium in immunocompetent and immunodeficient children: a prospective study. Pediatr Infect Dis J 1995; 14: 1042-7.

59. Vargas SL, Shenep JL, Flynn PM, Pui CH, Santana VM, Hughes WT. Azytromicin for treatment of severe Cryptosporidium diarrhea in two children with cancer. J Pediatr 1993; 123: 154-6.

60. Armitage K, Flanigan T, Carey J, Frank I, MacGregor RR, Ross P, Goodgame R, Turner J. Treatment of cryptosporidiasis with paramomycin. A report of five cases. Arch Intern Med 1992; 152: 2497-9.

61. Cooper ES, Spencer J, White-Alleng CA, Cromwell O, Whitney P, Venugopal S, Bundy DA, Haynes B, MacDonald TT. Immediate hypersensitivity in colon of children with chronic Trichuris trichiura dysentery. Lancet 1991; 338: 1104-7.

62. Walden J. Parasitic diseases. Other roudworms. Trichuris, hookworm, and Strongyloides. Prim Care 1991; 18 :5374.

63. De Paola D, Braga-Dias L, da Silva JR. Enteritis due to Strongiloides stercoralis. Am J Dig Dis 1962; 7: 108698.

64. Taranto NJ. Strongiloides stercoralis. Reporte de un caso y revision de la literatura. Acta Gastroenterol Latinoam 1995; 25: 113-20.

65. Carvalho Filho E. Strongyloidiasis. Clin Gastroenterol 1978; 7: 179-200.

66. Kane MG, Luby JP, Krejs GJ. Intestinal secretion as a cause of hypokalemia and cardiac arrest in a patient with strongyloidiasis. Dig Dis Sci 1984; 29: 768-72.
67. Milner PF, Irvine RA, Barton CJ, Bras G, Richards R. Intestinal malabsorption in Strongyloides stercoralis infestation. Gut 1965; 6: 574-81.

68. Laudanna AA, Polack M, Betarello A, Kieffer J. Evidence of protein-losing enteropathy in strongyloidiasis. Rev Inst Med Trop São Paulo 1973; 15: 222-6.

69. Igra-Siegman Y, Kapila R, Sen P, Kaminski ZC, Louria DB. Syndrome of hyperinfection with Strongyloides stercoralis. Rev Infect Dis 1981; 3: 397-407.

70. Pereira Lima J, Delgado PG. Diagnosis of strongyloidiasis: importance of Baermann's method. Am J Dig Dis 1961; 6: 899-904.

71. Genta RM. Strongyloides stercoralis. In: Blaser MJ, Smith PD, Ravdin JI, Greenberg HB, Guerrant RL, editors. Infections of the gastrointestinal tract. New York: Raven; 1995. Chap 79, p. 1197-207.

72. Lambertucci JR. Acute schistosomiasis: clinical, diagnostic and therapeutic features. Rev Inst Med Trop São Paulo 1983; 35: 399-404.

73. King C, Mahmoud AF. Schistosomiasis. In: Blaser MJ, Smith PD, Ravdin JI, Greenberg HB, Guerrant RL, editors. Infections of the gastrointestinal tract. New York: Raven; 1995. Chap 80, p.1209-22.

74. King CH, Mahmoud AA. Drugs five years later: praziquantel. Ann Intern Med 1989; 110: 290.

75. Hall A. Intestinal parasitic worms and the growth of children. Trans R Soc Trop Med Hyg 1993; 87: 241-2.

Recebido em 18 de fevereiro de 2002

Versão final reapresentada em 17 de julho de 2002

Aprovado em 25 de julho de 2002 